\title{
Conceptions of Height and Verticality in the History of Skyscrapers and Skylines
}

\author{
Oksana Maslovskaya ${ }^{1 *}$, and Grigoriy Ignatov $^{1}$ \\ ${ }^{1}$ Far Eastern Federal University, 690900, 8 Sukhanova St., Vladivostok, Russia
}

\begin{abstract}
The main goal of this article is to reveal the significance of height and verticality history of skyscrapers and skylines. The objectives are as follows: 1. trace the origin of design concepts related to skyscraper; 2 . discuss the perceived experience of the cultural aspects of skyscrapers and skylines; 3. describe the differences and similarities of the profiles of with comparable skylines. The methodology of study is designed to explore the perceived theory and principals of skyscraper and skyline development phenomenon and its key features. The skyscraper reveals an assertive creative form of vertical design. Skyscraper construction also relates to the origin of ancient cultural symbolism as the dominant vertical element as the main features of an ordered space. The historical idea of height reaches back to the earliest civilization such as the Tower of Babel. Philosophical approaches of elements of such post-structuralism have been included in studying of skyscraper phenomenon. The analysis of skyscraper and their resulting skyline are examined to show the connection to their origins with their concepts of height and verticality. From the historical perspective, cities with skyscrapers and a skyline turn out to be an assertive manifestation of common ideas of height and verticality.
\end{abstract}

\section{Introduction}

Creating a city image has always been one of the primary concerns of architectural thinking, because cities of the world, like people, want to be significant and recognizable. Figuratively speaking, sometimes they want to be ascended to the sky. If historical towns are satisfactorily served by the clock and bell towers, fire watchtowers and church steeples, the key to the image of the megacities is the system of very tall buildings such as skyscrapers. The skyscraper cities are easily distinguishable, because they, like Gothic cathedrals, rush into the sky.

The main goal of this article is to reveal the significance of height and verticality history of skyscrapers and skylines. The objectives are as follows: 1. trace the origin of design concepts related to skyscraper; 2. discuss the perceived experience of the cultural aspects of skyscrapers and skylines; 3 . describe the differences and similarities of the profiles of with comparable skylines.

This study is based on works of theorists devoted to problems of contemporary high-rise architecture and urban-planning. The problems of the form and stylistics, symbolic values,

* Corresponding author: oxym69@gmail.com 
and ideology of skyscraper are discussed in critical and theoretical researches of such authors as Louis Sullivan [1], Hugh Ferriss [2], Alfred Bossom [3], Charles Jencks [4], Ada Louise Huxtable [5] and others. History of skyscraper and skyline phenomena is considered in works of Francisco Mujica [6], Christopher Tunnard [7], Judith Dupre [8], Paul Goldberger [9], James Giblin [10], John Zukowsky [11], Joseph Korom [12], etc.

Groups of skyscrapers as a whole, as well as 'skyline' as the concept for its aesthetic and socio-cultural interpretations, are analyzed in works of Wayne Attoe [13], L.R. Ford [14], Thomas A. P.van Leeuwen [15] and others. A number of $21^{\text {st }}$-century researchers deal with skylines of certain cities: London [16, 17], Kuala Lumpur [18], Saint Petersburg [19, 20], Moscow and other Russian cities [21], Istambul [22], Dubai [23], etc. The problems of height are highlighted in works of Louis Sullivan [1], Thomas A. P.van Leeuwen [15], Joseph Korom [12] and others. The problems of verticality are emphasized in works of various authors, among them Thomas A. P.van Leeuwen [15], Ada Louise Huxtable [5], Philip Nobel [24] etc.

\section{Methods}

The methodology of the study is based on principles of the semiotic approach developed by Roman Jakobson, J.M. Lotman, O.M. Freidenberg [25] etc., opening semantic features and the importance of the studied phenomenon in the system of culture. The wider phenomenological approach of Christian Norberg-Schulz [26] and Juhani Pallasmaa [27], which is taking into account not only realized architectural and town-planning objects but also non-realized or not intended for realization architectural projects, images, and ideas expressed in literary works, graphic and painting, movies and a theatrical art. Philosophical approaches of elements of Roland Barthes [28] post-structuralism have been included in studying of skyscraper phenomenon as well.

\section{Results}

The skyscraper reveals an assertive creative form of vertical design. Skyscraper construction also relates to the origin of ancient cultural symbolism as the dominant vertical element as the main features of an ordered space. The historical idea of height reaches back to the earliest civilization such as the Tower of Babel. Philosophical approaches of elements of such post-structuralism have been included in studying of skyscraper phenomenon. The analysis of skyscraper and their resulting skyline are examined to show the connection to their origins with their concepts of height and verticality.

Table 1. Comparative analysis of skyline, silhouette, horizon, and panorama notions.

\begin{tabular}{|l|c|c|c|c|}
\hline Image character & Skyline & Silhouette & Horizon & Panorama \\
\hline High (H) vs. Wideness (W) & H & H & W & W \\
\hline Dynamism (D) vs. Statics (S) & D & D & S & S \\
\hline Verticality (V) vs. Horizontality (Z) & V & V & Z & Z \\
\hline Multi-Layered (L) vs. Flat (F) & L & F & F & L \\
\hline Includes City Scenes & - & - & - & + \\
\hline Involves Architectural Matter & + & - & + & + \\
\hline
\end{tabular}




\section{Discussion.}

\subsection{Semantization of skyscraper and skyline notions}

According to Bible and Russian researcher Olga Freidenberg in her book Image and Concept: Mythopoetic Roots of Literature [25], in beginning was the Word, a sign-symbol without pragmatic content. Then it becomes a conventional notion or an operational concept, and only after this transformation is possible to reach a prosaic non-symbolic reality. Let us consider this rule concerning several notions linked with the conception of verticality.

Terms most commonly associated with the idea of height and conception of verticality in architecture are skyline and skyscraper. "Skylines are largely a $20^{\text {th }}$-century concern" [13]. However, this word was used earlier to describe not architectural, but the natural phenomenon. Originally, in the English language skyline meant "horizon" or "outline on the background of the sky." The first general use of the word skyline is recorded in 1824 when it appeared as a synonym for the horizon, the line where earth and sky meet [29]. "In travel literature - journals, diaries, and guidebooks - and in novels about travel and exotic places, 'skyline' was employed in reference to the meeting of sky and land" [13].

In American culture, the word skyline has gained a new and more specific architectural meaning: "outline of skyscrapers on the background of the sky." The use of the word skyline as "the outline or silhouette of a building or number of buildings or other subject seen against the sky" for the first time appeared in writings of George Bernard Shaw at the end of the 19th century [30]. Skyline has gotten a new underlying sense, a secondary architecture-poetical meaning.

Undoubtedly, this derivative developed only after the emergence of such specific architectural term as the skyscraper. The word skyscraper was used in 18-19 ${ }^{\text {th }}$ centuries to describe notions linked with human activity, but not yet in the architectural sense. Skyscraper was originally used in various senses: high-standing horse (1788); a triangular sky sail (1794); a tall hat or bonnet (1800); an exaggerated or "tall" story (1841); a very tall man (1857); in baseball a ball propelled high into the air, a towering hit, a skier (1866); a tall ornament on top of a building (1883); a rider on one of the high cycles formerly in use around 1892 [30]. Old and contemporary senses of the word skyscraper have in common the idea of height and verticality.

The term cloud scraper as an alternative notion for tall building description was introduced by Minneapolis architect L. S. Buffington in 1880-s. He studied the idea of steel skeleton application for construction of high-altitude buildings at a level of sketches and engineering calculations of 30, 50 and even 100-storeyed towers [10]. In 1887, the inventor has patented his cloud scrapers. Buffington "brought the potential of the iron skeletal frame to the attention of the national architectural and building communities" [31], but the neologism cloud-scraper has not got accustomed.

Charles Jencks in his book Skyscrapers-Skyprickers-Skycities [4] introduced some more notions for different types of high-rise buildings and complexes. Skypricker stands for a "skyscraper with a pointed spire" [32]. However, this term has not got accustomed. Skycity is determined by Jencks as a "the compound tall building" [4]. Contemporary using the word skycity includes names of games (one of the science fiction tabletop games has name "War of the Sky Cities"), films, firms, restaurants, casinos, big skyscrapers, airports etc.

We consider skycity as an opposition to solitaire, stand alone building (even if it is big and composite vertical city as Abeno Harukas in Japan, discussed by K. Mizutani, K. Hirakawa, M. Nakashima [33]); skycity is rather a city with skyscraper's clusters. Some contemporary researchers use the term Skyscraper City in similar meaning. For example, Prof. Terri Boake writes, "The increase in density of our urban environment as we create 
"skyscraper cities" is inevitable and desired as a means to limit urban sprawl and preserve valuable agricultural land" [34].

\subsection{Idea of height}

Modern skyscrapers and their clusters had emerged at the turn of the $19^{\text {th }}$ and the $20^{\text {th }}$ century in America. At that date architects and artists of America conducted active searches of the national identity and "new" city's architectonic. The idea of height was principally actual. In the search of skyscraper's style, the central attention was given to the height of its structure. In 1896 Louis Sullivan wrote, "What is the chief characteristic of the tall office building? And at once we answer, it is lofty. This loftiness is to the artist-nature its thrilling aspect. It is the very open organ-tone in its appeal. It must be in turn the dominant chord in his expression of it, the true excitant of his imagination. It must be tall, every inch of it tall. The force and power of altitude must be in it the glory and pride of exaltation must be in it. It must be every inch a proud and soaring thing, rising in sheer exultation that from bottom to top it is a unit without a single dissenting line, - that it is the new, the unexpected, the eloquent peroration of most bald, most sinister, most forbidding conditions" [1].

Dutch researcher Thomas A. P. van Leeuwen in his book The Skyward Trend of Thought: Metaphysics of the American Skyscraper considers skyscraper not only as innovative structure, but as well "as a late, but rightly timed, example of paradigmatic architecture; indeed as the tower of cosmogony" [15]. He believes that skyscraper is a modern successor of Tower of Babel: "Skyscrapers were the fulfillment of the Babylonian promise; the realization of both its technical enigma and its utopian-cosmopolitan objective" [15].

One of the first examples of such stepped form and skyrocket striving we can see in the fantastic view of Erastus Salisbury Field's painting of 1876 named "The Historical Monument of the American Republic." One of the latest examples is the Le Royal [35], $7^{\text {th }}$ tallest building in Amman, Jordan, completed in 2003.

As Thomas A. P. van Leeuwen notes, "The non-conscious knowledge or intuition is probably what the old tower builders and originators of the first American skyscrapers had in common: an enthusiastic, non-rational, desire to build high in celebration of something that probably they were not aware of" [15].

The concept of height becomes the basic sense of skyscraper. As J.J. Korom shows, "We celebrate the push upward to be nearer the clouds and we celebrate our tussle with nature, gratified it allows us the notion of supremacy. We can now build higher than ever before and realize the celebration of the height is primal and constant" [12]. The concept of height summarizes the essence of all possible kinds of height. More precisely, it embodies the idea of height. The form of skyscraper itself does not make any deep spirit, it is included in one or other pragmatic context directed on the realization of certain practical function. It is possible to say that height is concept in the absolute. The interconnected idea of being "No. 1" is embodied in architecture in the constantly updated lists of the word tallest buildings - symbols of maximum achievements.

The idea of height is excluded from any context; it is organic, immanent to the human, deep architectonic sense as such. The basic concept of height is used not only in architecture; it is performed in other arts. As Roland Barthes wrote, "This common domain of the signifieds of connotation is that of ideology, which cannot but be single for a given society and history, no matter what signifiers of connotation it may use" [28]. Thus, the concept of height belongs to the ideology extending on all manifestations of culture because the area of ideology is common for all signified senses. 
Moreover, as Thomas A. P. van Leeuwen writes, " $19^{\text {th }}$-century Americans, as well as Babylonians, had shared the common realm of platonic ideas, from which they had derived their ambitions as well as their concept of verticality" [15].

\subsection{Verticality as a creative assertive gesture}

Many theorists connect vertical character of skyscrapers with the deep initial, primitive senses of architecture. As Philip Nobel notes, "there's something driving the height race. Something primal, competitive, romantic, eternal: some consequence of human minds, hard-wired to love a prospect, a mountain, needing to be high to feel safe from threat, congenitally driven to manufacture a marker on the land - the higher the better, and better still if it can be the highest of them all" [24].

Ada Louise Huxtable asserts, "From the Tower of Babel onward, the fantasies of builders have been vertical rather than horizontal" [5]. By themselves, the tower and skyscraper due to the rising form, reveal the phenomenological meaning of verticality since it represents a creative assertive gesture. It fulfills the requirement of certain efforts to maintain the stability of a vertical position, which means activity and strength in comparison with the less "energy-consuming" horizontal position symbolizing calm and relaxation.

This phenomenological meaning of skyscraper's and medieval tower's cities is expressed also, for example, in such tectonic games as the erection of a tower from playing cards, tower piles of children's cubes or sand castles. As Thomas A. P. van Leeuwen asserts, "From that days to this, whenever men have become skillful architect at all, there has been a tendency in them to built high; not it any religious feeling, but in mere exuberance of spirit and power - as they dance or sing - with a certain mingling of vanity like a child builds a tower of cards" [15].

Hence, skyscraper construction also relates to the origin of ancient cultural symbolism as the dominant vertical element as the main feature of an ordered space. The vertical development of the city space gives it a "new" architectonics - the symbolic dimension, outwardly invisible to the eye, which can be comprehended by the set of additional analytical interpretations.

\subsection{Comparative analysis of skyline, silhouette, horizon, and panorama notions}

The wide range of terms related to observing cities from different points of view exists in the English language. View of city, bird's eye view, and worm's eye view, silhouette of city, panorama, vista, cityscape, skyline and horizon are among them. The objective of this paragraph is to state differences and similarities of some this notions.

Beside panorama, skyline is characterized by larger height, compactness, and dynamism of depictured urban architectonic. At the same time panorama has large spaciousness, the wide-format scope of territories and static character of depictured urban form.

Skyline in its contemporary meaning and horizon are the characteristic projections of the vertical and horizontal, volumetric and linear, dynamic and static city's views.

Skyline is closest to the silhouette because of its dynamism and other qualities of the described forms. Nevertheless, the silhouette is the undifferentiated mass, filled outline, while skyline is multi-layered, the mosaic collage of forms, ornamentation, textures, styles. Silhouette can be applied to any, even not architectural object, for example, silhouette of vase or the silhouette of man, while skyline already implies architectural matter, since it means the "outline of the groups of skyscrapers against the background of sky." 
Panorama can be interpreted as panorama of urban life, city scene or urban picture, where the everyday or holiday life of city may be depictured, including the typical urban elements, the motion of people and automobiles. Skyline and silhouette of city are more outlines of cityscape than a city scene in this matter.

Skyline comprises the wide range of the city's views: with upper, frontal, internal, even worm's eye points of observation. City's silhouette can be described only as a special mode of skyline in this matter, because it cannot be, for example, the upper view.

Most significantly, skyline belongs to the non-classical system of esthetic values. New symbolism and the artistic methods of collage (as discussed by Colin Rowe in Collage city [36]) accumulation and assemblage lie at the basis of its polycentric organization.

\section{Conclusion}

For a long time, skyscraper cities and skyline was characterized as an object of the American national and territorial identity. Since the 1950s, this city planning phenomenon as the unconscious realization of the archetype of 'tower city' was extended throughout the world. From the historical perspective, cities with skyscrapers and a skyline turn out to be an assertive manifestation of common ideas of height and verticality.

\section{References}

1. L. Sullivan, The tall office building artistically considered The public papers, R, Jwombly (ed.). (University of Chicago Press, Chicago, London, 1988)

2. H. Ferriss, The metropolis of tomorrow (Princeton Architectural Press, Princeton, NJ, 1986)

3. A. Bossom, Building to the Skies, the Romance of the Skyscraper (The Studio, New York, 1934)

4. Ch. Jencks, Skyscrapers-Skyprickers-Skycities (New York, Rizzoli, 1980)

5. A. L. Huxtable, The tall building artistically reconsidered: the search for a skyscraper style (Pantheon Books, New York, 1984)

6. F. Mujica, History of the Skyscraper (Archeology and Architecture Press, New York, 1930)

7. Chr. Tunnard, H. H. Reed, American skyline; the growth and form of our cities and towns (Houghton Mifflin, Boston, 1955)

8. J. Dupre, Skyscrapers, (Black Dog \& Leventhal, New York, 1996)

9. P. Goldberger, The skyscraper (Knopf, New York, 1981)

10. J. C. Giblin, The skyscraper book (Crowell, New York, 1981)

11. J. Zukowsky, The Sky's the limit: a century of Chicago skyscrapers (Rizzoli, New York, 1990)

12. J. J. Korom, The American Skyscraper, 1850-1940: A Celebration of Height (Branden Books, 2008)

13. W. Attoe, Skylines: understanding and molding urban silhouettes (Wiley, Chichester, New York, 1981)

14. L. R. Ford, The Urban Skyline As A City Classification System, Journal of Geography 75.3, 154-164 (1976)

15. T. A. P. van Leeuwen, The skyward trend of thought: the metaphysics of the American skyscraper (MIT Press, Cambridge, Mass., 1988) 
16. R. Tavernor, Visual and cultural sustainability: The impact of tall buildings on London, Landscape and Urban Planning 83.1, 2-12 (2007)

17. R. Tavernor, G. Gassner, Visual consequences of the plan: Managing London's changing skyline, City, Culture and Society 1.2, 99-108 (2010)

18. N. A. H. Yusoff, A. M. Noor, R. Ghazali, City Skyline Conservation: Sustaining the Premier Image of Kuala Lumpur, Procedia Environmental Sciences, 20, 583-592, (2014)

19. N.S. Trumbull, St. Petersburg, Russian Federation, Cities, 31, 469-490, (2013)

20. M. Dixon, Gazprom versus the Skyline: Spatial Displacement and Social Contention in St.Petersburg, International Journal of Urban and Regional Research 34.1, 35-54, (2010)

21. G.A. Ptichnikova, New Century High Risers in the Core Areas of Historic Cities in Russia, Procedia Engineering 165, 1903-1910, (2016)

22. C. Guney, S.A. Girginkaya, G. Cagdas, S. Yavuz, Tailoring a geomodel for analyzing an urban skyline, Landscape and Urban Planning, 105, 160-173, (2012)

23. M. Acuto, High-rise Dubai urban entrepreneurialism and the technology of symbolic power, Cities 27.4, 272-284, (2010)

24. P. Nobel [Editor], The Future of the Skyscraper (Metropolis Books, 2015).

25. O. Freidenberg, Image and Concept: Mythopoetic Roots of Literature, (Taylor \& Francis, 1997)

26. Chr. Norberg-Schulz, Genius Loci: Towards a Phenomenology of Architecture (Rizzoli, New York, 1979).

27. J. Pallasmaa, The geometry of feeling: a look at the phenomenology of architecture Theorizing a new agenda for architecture: an anthology of architectural theory 19651995, Nesbitt, Kate (ed.). (Princeton Architectural Press, New York, 1996)

28. R. Barthes, Rhetorique de I'image, Communications 4, 49, (1964)

29. R.K. Barnhart [editor], and S. Steinmetz [managing editor]; The Barnhart dictionary of etymology (Wilson Co., Bronx, N.Y., H.W., 1988)

30. J.A. Simpson, and E.S.C. Weiner [prepared by]; The Oxford English dictionary; 2nd ed. (Oxford University Press, Oxford, Clarendon Press; New York, 1989)

31. http://www.minnesotainventors.org/inductees/leroy-buffington.html (last accessed 2017.07.16)

32. http://www.skyscraperdictionary.com/?project=skypricker (last accessed 2017.07.16)

33. K. Mizutani, K. Hirakawa, and M. Nakashima, Construction of a 300-Meter Vertical City: Abeno Harukas, International Journal of High-Rise Buildings 4.3, 199-207, (2015)

34. T.M. Boake, It's Not About the Skyline, It's About the Base Condition, Global Interchanges: Resurgence of the Skyscraper City, CTBUH 2015 New York Conference, 494-501, (2015)

35. S. Abu-Ghazalah, Le Royal in Amman: A new architectural symbol for the $21 \mathrm{st}$ century, Cities, 23.2, 149-159 (2006)

36. C. Rowe, F. Koetter, Collage city (MIT Press, Cambridge, Mass., 1995) 